\title{
IDEAL-Cell, an Innovative Dual mEmbrAne fueL-Cell: Fabrication and Electrochemical Testing of First Prototypes
}

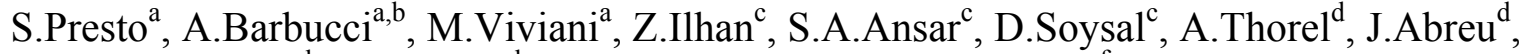

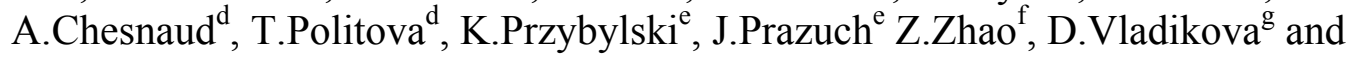 \\ Z.Stoynov ${ }^{\mathrm{g}}$ \\ ${ }^{a}$ Institute for ENergetics and Interphases (IENI-CNR), National Research Council, Via \\ De Marini 6, 16149 Genova, ITALY \\ ${ }^{\mathrm{b}}$ Department of Chemical and Process Engineering (DICHeP), University of Genova, \\ P.le Kennedy 1, 16129 Genova, ITALY \\ ${ }^{\mathrm{c}}$ German Aerospace Center (DLR-ITT) Pfaffenwaldring 38-40, Stuttgart D-70569, \\ GERMANY \\ ${ }^{\mathrm{d}}$ Centre des Matériaux, Mines-ParisTech, BP87, Evry Cedex 91003, FRANCE \\ ${ }^{\mathrm{e}}$ Department of Solid State Chemistry, AGH University of Science \& Technology, Al \\ Mickiewicza 30, PL-30059 Krakow, POLAND \\ ${ }^{\mathrm{f}}$ Arrhenius Laboratories, University of Stockholm, S-10691 Stockholm, SWEDEN \\ ${ }^{\mathrm{g}}$ Institute of Electrochemistry and Energy Systems - BAS, 10 Acad. G. Bonchev St., \\ Sofia 1113, BULGARIA
}

The IDEAL-Cell concept is based on the junction between a PCFC anode/electrolyte section and a SOFC cathode/electrolyte section, through a mixed proton and oxide ion conducting porous ceramic membrane, operating in the temperature range $600-700^{\circ} \mathrm{C}$. Recombination of ions takes place within the junction, or central membrane $(\mathrm{CM})$, and water vapor is evacuated through open porosity.

The first results on the fabrication of multilayered samples reproducing the IDEAL-Cell structure are reported here, together with electrochemical tests carried out on selected samples in order to evaluate the performances of the chosen materials and to demonstrate the feasibility of this innovative concept of fuel cell.

Stable OCV and power generation were obtained in the multilayered structures. Anomalies on the I/V curves and impedance measurements under large perturbation could be considered as proofs of water formation inside the central membrane.

\section{Introduction}

When compared to other Fuel Cells types, solid oxide fuel cells (SOFC) and proton conducting solid oxide fuel cells (PCFC) offer several advantages, mainly related to efficiency and multi-fuel operation, but also limitations that slow down their marketing (1). The elevated temperature (in the range $800-1000{ }^{\circ} \mathrm{C}$ ) required for SOFCs causes failure upon thermal cycling and long term operation. PCFCs also present significant pitfalls: operating at lower temperature (about $600{ }^{\circ} \mathrm{C}$ ) and potentially much more 
efficient than SOFC, they nevertheless suffer from a lack of adequate cathode materials. A weak point, common to both configurations, is the dilution of reacting gases, at the anode side in SOFCs and at the cathode side in PCFCs. In order to overcome such limitations, an innovative cell architecture was proposed (2). The IDEAL-Cell concept is based on the joining of a PCFC anode/PCFC electrolyte part (anode compartment) with a SOFC electrolyte/SOFC cathode (cathode compartment), through a mixed $\mathrm{H}^{+}$and $\mathrm{O}^{2-}$ conducting porous ceramic central membrane $(\mathrm{CM})$, made of a composite based on both PCFC and SOFC electrolytes and operating in the range $600-700{ }^{\circ} \mathrm{C}$. In its simplest form, the IDEAL-Cell consists of a multilayered planar structure, each layer having proper composition and porosity. Electrolytes must be gas tight and ideally possess unit or zero transport number for the relevant ionic species, i.e. $\mathrm{H}^{+}$and $\mathrm{O}^{2-}$. The central membrane should have high conductivity for both ionic species, large exchange -regions for efficient ions recombination and significantly large open porosity for water vapor removal, as also indicated by modeling results (3). The fabrication of ceramic multilayers can be approached by several techniques, basically depending on the required thickness of layers and the thermo-mechanical properties of different materials. Shaping of films of intermediate thickness, in the range 10-400 $\mu \mathrm{m}$, can be efficiently achieved either by Tape Casting (TC), screen-printing (SP) or Plasma Spraying (PS). For bulk-like structures, i.e. for layer thickness $>500 \mu \mathrm{m}$, cold-pressing techniques become viable. A thermal treatment at temperatures in the range of $1000{ }^{\circ} \mathrm{C}$ is then required to obtain dense layers. The combination of different materials in the same structure involves a number of problems of chemical compatibility (4) and of mechanical stability due to different shrinkage behaviours during the sintering stage and different Thermal Expansion Coefficients (5). Mechanical compatibility problems can be mitigated by the addition of sintering aids, i.e. by introducing small amounts $(0.5-5 \%)$ of elements acting as densification promoters, without modifying the composition and the properties of the hosting structure. Such elements become effective when located at grain boundaries, where a transient liquid phase is generally formed, eventually followed by evaporation of most of the additive. Proper selection of additives can reduce the sintering temperature by $100-150{ }^{\circ} \mathrm{C}$ and improve plasticity of layers. One example is given by $\mathrm{CuO}$ and $\mathrm{V}_{2} \mathrm{O}_{5}$, which were successfully used for the densification of Niobates and $\mathrm{BaCeO}_{3}$ (6). Significant diminishing of the sintering temperature can be also obtained by Hot Pressing (HP) and Spark Plasma Sintering (SPS), which allow the fabrication of dense finegrained ceramics and composite materials $(7,8)$. In this work, various techniques were implemented to fabricate different dedicated samples or cell components, each having their own purpose in the frame of the IDEAL-Cell project; the samples were:

- Proof of Concept (PoC) samples, made of a thick central membrane (CM; porous oxygen and hydrogen electrolytes composite) sandwiched between the two types of electrolytes $\left(\mathrm{H}^{+}\right.$and $\left.\mathrm{O}^{2-}\right)$, both thick; PoC samples were made either via cold-pressing or SPS, and their purpose is to verify the proof of concept criteria defined in (2);

- Preliminary complete IDEAL-Cell samples, made of the full sequence of the five thin layers of the concept, deposited and stacked via tape-casting; their purpose is to check the feasibility of the IDEAL-Cells shaping via a low cost technique;

- single Oxygen Electrolyte, samples made by CP, in order to evaluate the electrical properties of the oxygen electrolyte, and to serve as the electrolyte for part of the half cells fabrication; 
- Cathodic Half Cell samples, made of a thick and dense $\mathrm{O}^{2-}$ electrolyte obtained either by $\mathrm{CP}$ or TC, sandwiched on both sides by the cathode material deposited either by TC or PS (9); their purpose is to evaluate and optimize the electrochemical properties of the cathodic compartment;

Shaping procedures and microstructure analyses of all these samples and components are given in the following sections; the first electrochemical results on the $\mathrm{PoC}$ samples, as validation of the IDEAL-Cell concept, are reported elsewhere (2).

\section{Experimental procedures and samples preparation}

\section{$\underline{\text { Starting powders }}$}

Fine powders of $\mathrm{Ce}_{0.85} \mathrm{Y}_{0.15} \mathrm{O}_{1.925}$ (YDC, oxygen conductor) and $\mathrm{BaCe}_{0.85} \mathrm{Y}_{0.15} \mathrm{O}_{2.925}$ (BCY, proton conductor) with average particle size of about $0.3 \mu \mathrm{m}$ were prepared by the oxalate precipitation route for electrolyte layers, while coarser $\mathrm{La}_{0.6} \mathrm{Sr}_{0.4} \mathrm{Co}_{0.2} \mathrm{Fe}_{0.8} \mathrm{O}_{2.8}$ (LSCF48, cathode) and $\mathrm{La}_{0.60} \mathrm{Sr}_{0.40} \mathrm{CoO}_{2.80}$ (LSCF40, cathode) powders were obtained by a self-combustion process. Before any processing (CP, SP or TP), powders were ball milled overnight and sieved. Cathode material powders for thermal spray deposition were specifically granulated.

\section{Proof of Concept $(\mathrm{PoC})$ samples}

Thick pellets were obtained by uniaxial cold pressing of 1-3 $\mathrm{g}$ of powders, in some cases added with a binder PVA (1 wt.\%), at $60 \mathrm{MPa}$ for $1 \mathrm{~min}$. Two strategies were explored for the fabrication of PoC multilayers (dense YDC15/CM/dense BCY15), i.e. a) co-pressing of layers, realized by piling up different powders in the same dye, followed by co-sintering of the whole structure, $b$ ) joining of pre-sintered layers. In both cases a modification of the sintering behaviour of $\mathrm{BCY}$ and $\mathrm{YDC}$ was required in order to minimize shrinkage differences and/or improve adhesion within the $\mathrm{CM}$ and between the layers. Sintering tests at different temperatures were carried out on YDC and BCY doped with $\mathrm{B}_{2} \mathrm{O}_{3}$ and/or $\mathrm{Li}_{2} \mathrm{CO}_{3}$. Final density was evaluated by the immersion technique in isopropanol. As a result, doped YDC and BCY powders were employed either to fabricate electrolyte and central membrane layers or to realise adhesion layers between electrolytes and the central membrane. Alternatively, thick PoC multilayers were prepared by SPS without any addition of sintering aids to the starting powders. The samples were heated up at $200^{\circ} \mathrm{C} / \mathrm{min}$ in a SPS equipment (Dr. Sinter 2050, Sumitomo Coal Mining Co., Tokyo, Japan) by allowing a pulsed direct current to pass through the pressure die, while an uniaxial pressure of $100 \mathrm{MPa}$ was continuously applied. Sintering was carried out in vacuum. The holding time at the sintering temperature $\left(1200^{\circ} \mathrm{C}\right)$ was about $2-5 \mathrm{~min}$. The porosity in the central membrane should be open to ensure efficient water vapour elimination through interconnected paths of pores. To this purpose three pore formers with different shape/size were used, i.e. spherical particles of corn starch (Aldrich, $\mathrm{d}_{50}=10 \mu \mathrm{m}$ ) or platelets of graphite (Timrex, KS5-44 $\mathrm{d}_{50}=27 \mu \mathrm{m}, \mathrm{KS} 6 \mathrm{~d}_{50}=3$ $\mu \mathrm{m})$. The total amount of pore forming agent was always in the range $30-50 \mathrm{vol} . \%$ and the ratio $\mathrm{BCY} / \mathrm{YDC}$ in the solid phase was equal to 1 , in order to ensure the percolation of the three phases present in the membrane. The pore formers are completely eliminated by a thermal treatment in air at $650^{\circ} \mathrm{C}$ for $2 \mathrm{~h}$. 


\section{$\underline{\text { Complete IDEAL-Cell samples }}$}

The fabrication of a complete cell samples was attempted by tape casting (TC) and co-sintering. TC is a low cost technique that allows both an excellent control of the tape microstructure via the slurry composition and thermal treatment, and makes the stacking of green tapes easy to obtain a flat multilayered component. In our case, green tapes were deposited on a glass substrate one on top of the other with the sequence anode/hydrogen electrolyte/CM/oxygen electrolyte/cathode. Glycerol was deposited as a film on the glass surface, and added to the anode slurry to avoid any adhesion between the substrate and the green stack. First a $500 \mu \mathrm{m}$ thick anode tape was cast on the glass substrate, then left 20 minutes at room temperature for the drying process to take place. The other layers were deposited following the same procedure. The assembly of green tapes was then fully dried at room temperature for two additional hours before being cut into discs. The complete discs assembly was then heated at $350^{\circ} \mathrm{C}$ for the decomposition of organic species, then heated up and sintered at $1350{ }^{\circ} \mathrm{C}$ for 5 hours. The slurry compositions are given in table 1; they are composed of the relevant powders, of the solvent (Ethanol), the binder (PVB), the plasticizer (PEG) and graphite as pore former for the $\mathrm{CM}$ and the cathode. As it is seen in the previous section, co-sintering necessitates that both intrinsic $\mathrm{BCY}$ and YDC sintering temperatures are brought as close as possible one to the other. In order to lower the BCY sintering temperature down to that of YDC without affecting the electrical properties, $1 \mathrm{wt} \% \mathrm{ZnO}$ was added to $\mathrm{BCY}$.

TABLE 1. Slurries composition used for the elaboration of the complete IDEAL-Cell by tape casting.

\begin{tabular}{lccccc}
\hline Constituent & Cathode & $\begin{array}{c}\text { Electrolyte } \\
\text { SOFC }\end{array}$ & $\begin{array}{c}\text { Central } \\
\text { Membrane }\end{array}$ & $\begin{array}{c}\text { Electrolyte } \\
\text { PCFC }\end{array}$ & Anode \\
\hline LSCF48 & $5.0 \mathrm{~g}$ & - & - & - & - \\
YDC & - & $6.0 \mathrm{~g}$ & $3.0 \mathrm{~g}$ & - & - \\
$\mathrm{BCY}$ & - & - & $3.0 \mathrm{~g}$ & $6.0 \mathrm{~g}$ & $2.5 \mathrm{~g}$ \\
$\mathrm{NiO}$ & - & - & - & - & $3.8 \mathrm{~g}$ \\
$\mathrm{ZnO}$ & - & - & - & $0.06 \mathrm{~g}$ & - \\
Ethanol & $4.5 \mathrm{~g}$ & $4.8 \mathrm{~g}$ & $7.0 \mathrm{~g}$ & $5.2 \mathrm{~g}$ & $6.0 \mathrm{~g}$ \\
PVB & $1.0 \mathrm{~g}$ & $1.4 \mathrm{~g}$ & $2.2 \mathrm{~g}$ & $1.4 \mathrm{~g}$ & $1.2 \mathrm{~g}$ \\
PEG & $0.25 \mathrm{~g}$ & $0.30 \mathrm{~g}$ & $0.40 \mathrm{~g}$ & $0.40 \mathrm{~g}$ & $0.40 \mathrm{~g}$ \\
Glycerol & - & - & - & - & $0.60 \mathrm{~g}$ \\
Graphite & $2.0 \mathrm{~g}$ & - & $1.2 \mathrm{~g}$ & - & \\
\hline
\end{tabular}

\section{$\underline{\text { Single Oxygen Electrolyte samples }}$}

YDC and BCY pellets were prepared by cold pressing under conditions that are given above for PoC samples. Green pellets were then sintered respectively at $1250^{\circ} \mathrm{C}$ and $1450^{\circ} \mathrm{C}$ for 8 hours. Electrical measurements on these samples were made with $\mathrm{Pt}$ electrodes.

\section{$\underline{\text { Cathodic Half Cell samples }}$}

Plasma spraying was selected to be one of the processes to be tested for its performance/applicability as an alternative to screen printing, which is the common one used today, for the oxygen electrode manufacturing for ceramic fuel cells. PS has been implemented in producing DLR planar metal supported complete SOFCs, which is a favourable technique in terms of short fabrication time and its simple automation. In this work the results of oxgen electrode developments by PS are presented. The electrode layer has to possess a defined gas permeability by having a homogeneous porosity 
throughout in order to achieve electrochemically active sites for reactions. Therefore the microstructure of the resulted layer plays an important role in defining the final performance. Then, in the case of PS the chemical composition as well as the microstructure of the feed stock powder effect the resulting performance of the layer. By adjusting the spraying parameters, the agglomerated and partially sintered feed stock powder was melted only slightly on the surface providing the adhesion of separate particles while preserving the porosity within the agglomerates. In this way it was possible to achieve high porosity for gas supply along with connected particle neck for a better electrical conductivity within the oxygen electrode. As a first step, we evaluated LSCF48 and compared it to the standard $\mathrm{La}_{0.80} \mathrm{Sr}_{0.20} \mathrm{MnO}_{3-\delta}$ (LSM) cathode material. Therefore, LSM and LSCF48 materials were deposited onto metal supported half SOFCs by plasma spraying and test them at $800{ }^{\circ} \mathrm{C}$ under SOFC operation conditions. Then, as a second step, oxygen electrodes were deposited by plasma spraying, symmetrically onto both sides of pre-sintered YDC substrates to form cathodic symmetrical half cells for a more detailed investigation. Cathodic half cell samples have also been prepared by the deposition of LSCF48 by tape casting on both sides of YDC samples under conditions similar to those given for the complete IDEAL-Cell samples. Comparison of the impedance response for cathodic half cell samples obtained with the deposition of the cathode either by PS or by TP has been achieved.

\section{$\underline{\text { Electrical measurements }}$}

Electrochemical impedance spectroscopy measurements were carried out at different temperatures both on cathodic half cells and on PoC samples. YDC electrolytes with LSCF48 electrodes were tested in air within a 4-wires rig with a 2-electrodes configuration. Pt wires and meshes were used as current collectors. BCY electrolytes with Pt electrodes were tested in humidified (3 wt.\%) $\mathrm{H}_{2}$ stream. The setup for PoC multilayers characterization is described in detail elsewhere (2).

\section{Results and discussion}

\section{Proof of concept samples and complete cells shaping}

Table 2 reports the density values obtained by introducing different amounts of sintering aids. In the case of YDC, the addition of $0.25 \mathrm{wt} \%$ of $\mathrm{B}_{2} \mathrm{O}_{3}$ and $1.25 \mathrm{wt} \%$ of $\mathrm{Li}_{2} \mathrm{CO}_{3}$ allows to reach almost full densification at $950{ }^{\circ} \mathrm{C}$, without formation of any secondary phases (figure 1a). A broader range of sintering aid compositions was tested with BCY. A significant reduction of the sintering temperature $\left(1100{ }^{\circ} \mathrm{C}\right)$ was observed when lithium carbonate addition exceeded 2 wt.\%. However, under such conditions acicular grains of yttrium oxide were also formed (Figure 1b).

TABLE 2. Effect of sintering aids on electrolyte materials.

\begin{tabular}{lcccc}
\hline Electrolyte & $\begin{array}{c}\mathbf{B}_{\mathbf{2}} \mathbf{O}_{\mathbf{3}} \\
/ \mathbf{w t . \%}\end{array}$ & $\begin{array}{c}\mathbf{L i}_{\mathbf{2}} \mathbf{C O}_{\mathbf{3}} \\
/ \mathbf{w t .} \%\end{array}$ & $\begin{array}{c}\mathbf{T} \text { sint } \\
{ }^{\mathbf{O}} \mathbf{C}\end{array}$ & $\begin{array}{c}\text { Relative density } \\
/ \%\end{array}$ \\
\hline YDC15 & - & - & 1150 & 97 \\
YDC15 & 0.25 & 1.25 & 950 & 98 \\
BCY15 & - & - & 1300 & 96 \\
BCY15 & 0.25 & 1.25 & 1200 & 89 \\
BCY15 & 0.25 & 2.0 & 1100 & 93 \\
BCY15 & 0.5 & 2.5 & 1100 & 97 \\
BCY15 & - & 2.5 & 1100 & 95 \\
BCY15 & 0.5 & - & 1100 & 85 \\
\hline
\end{tabular}




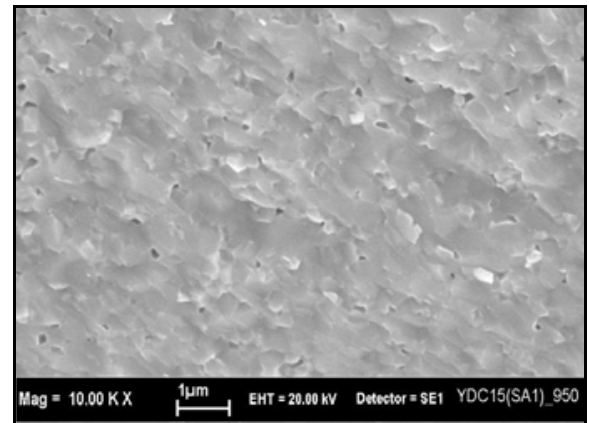

(a)

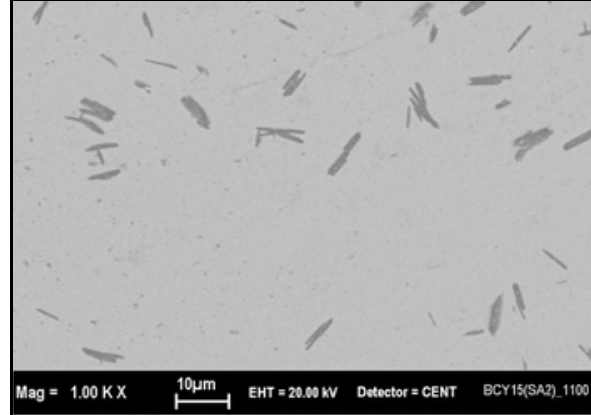

(b)

Figure 1. SEM images of YDC doped with $0.25+1.25$ wt. $\%$ of $\mathrm{B}_{2} \mathrm{O}_{3}+\mathrm{Li}_{2} \mathrm{CO}_{3}$, $\mathrm{T}_{\text {sint }}=950^{\circ} \mathrm{C}$ (a) and BCY doped with $0.5+2.5$ wt. $\%$ of $\mathrm{B}_{2} \mathrm{O}_{3}+\mathrm{Li}_{2} \mathrm{CO}_{3}, \mathrm{~T}_{\text {sint }}=1100^{\circ} \mathrm{C}(\mathrm{b})$

Figure 2 illustrates the microstructure of central membrane layers obtained by cold pressing of powders containing different pore forming agents. In fact the shape and size of pores are consistent with morphology of additives. Spherical starch particles tend to leave rounded cavities, sometimes elongated by the coalescence and deformation of several of them, separated by thin solid walls. On the contrary, graphite gives rise to large lens-shaped voids and much finer pores, depending on the size of the additive.
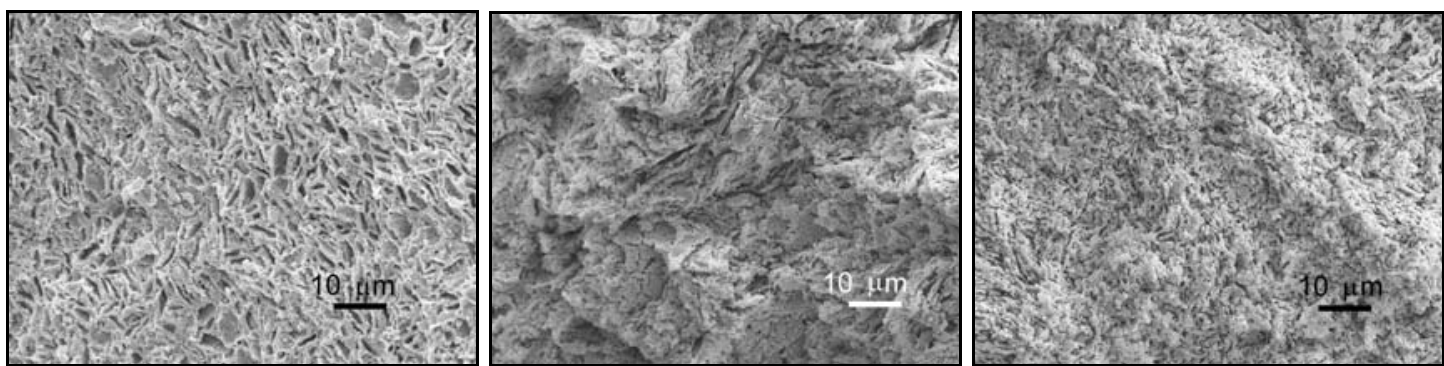

Figure 2. SEM images of central membrane layers added with 50 vol.\% of starch (left), coarse graphite (center) or fine graphite (right), $\mathrm{T}_{\text {sint }}=1100^{\circ} \mathrm{C}$

Thick PoC multilayers prepared by different techniques as described in the previous section were very fragile, sensitive to thermal cycling and exposition to atmosphere. Mechanical failure was frequently observed within single layers, together with debonding of joined layers. However, a few samples were stable enough for electrochemical testing and, therefore, for investigation of the IDEAL-Cell operation principle.
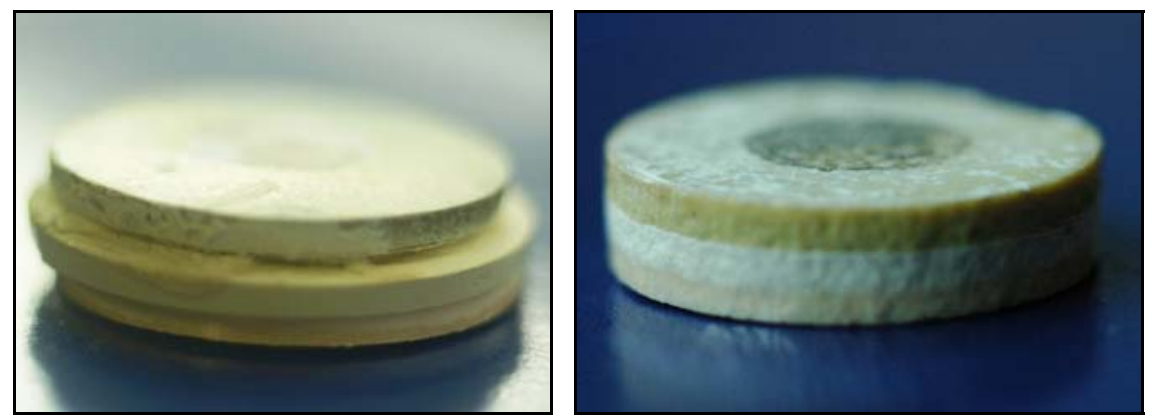

Figure 3. Photographs of PoC three-layers obtained by joining of pre-sintered pellets (left), SPS (right). In both cells the composition of layers is (from top): BCY/CM/YDC. 
Figure 3 shows two examples of such thick PoC three-layers, each made of two dense electrolytes separated by a porous central membrane layer. In general, SPS fabrication allowed a more regular shape and tight adhesion of layers. In addition, the pores in the central membrane of SPSed pellets were elongated along the radial direction, which should be most favourable for water vapour elimination. This interesting feature is clearly visible in figure 4, where the microstructure of the whole sample is shown.

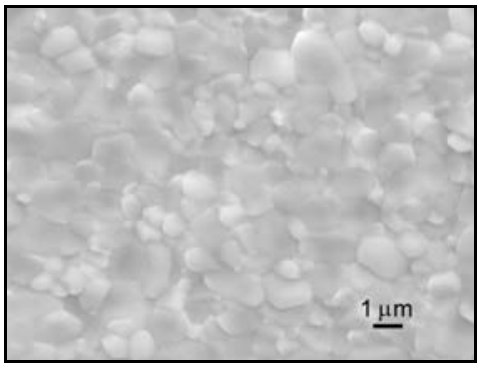

(a)

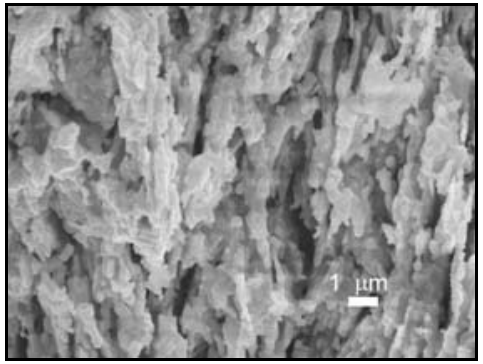

(b)

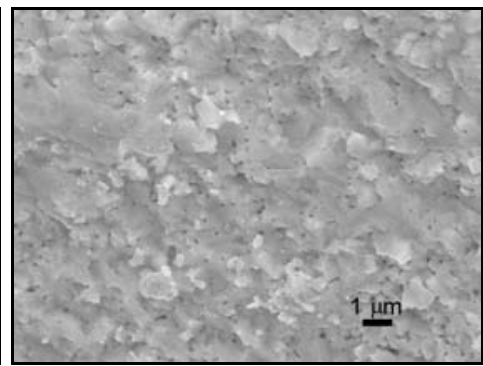

(c)

Figure 4. SEM images (section) of the three layers of a thick PoC sample fabricated by SPS: BCY (a), Central Membrane (b), YDC (c).

The fabrication of thin complete IDEAL-Cells was also attempted by tape casting. Figure 5 shows the cross section of a 5-layer tape sintered at $1250{ }^{\circ} \mathrm{C}$ for $2 \mathrm{~h}$ in air. SEMEDX analyses showed that layers are chemically stable (no significant interdiffusion). The adhesion of layers is good except for LSCF, which tends to be pulled out. Perpendicular cracking occurs also in YDC and LSCF48. The density is coherent with the IDEAL-Cell design (2) except for the BCY electrolyte layer (located between marks 3.5 and 6 on figure 5), which is highly porous.

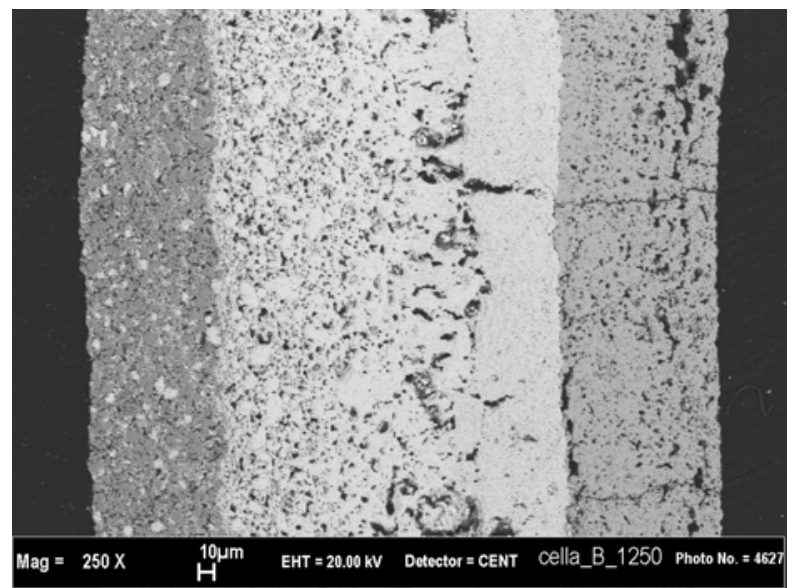

Figure 5. SEM cross-section image of a 5-layer complete cell fabricated by TC. The composition of layers is (from left): BCY-NiO/BCY/BCY-YDC/YDC/LSCF48.

\section{Evaluation of the oxygen electrode}

The first approach was to develop the perovskite layers of $\mathrm{La}_{0.80} \mathrm{Sr}_{0.20} \mathrm{MnO}_{3-\delta}$ (LSM) and LSCF materials and deposit these onto metal supported half SOFCs by plasma spraying and test these at $800^{\circ} \mathrm{C}$ under SOFC operation conditions. The electrical performance of the state of art plasma sprayed metal supported DLR-SOFCs has been increased by $75 \%$ already by switching to LSCF as cathode material instead of LSM, as reported in year 2008 at the DLR (9). An additional increase was achieved recently by 
using a newly implemented plasma torch (Triplex 200 Pro, Sulzer Metco, Switzerland) and granulated powders from Marion Technologies (Figure 6).

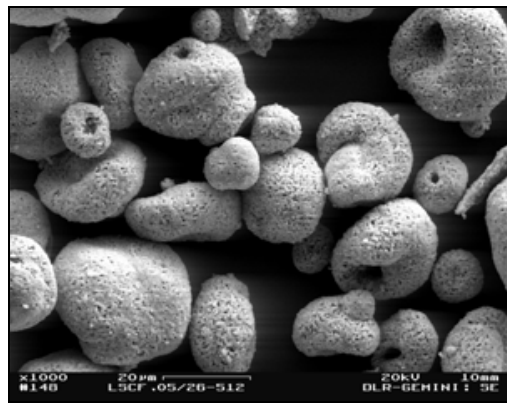

(a)

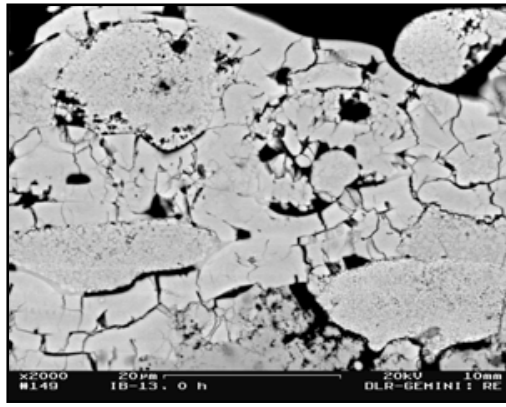

(b)

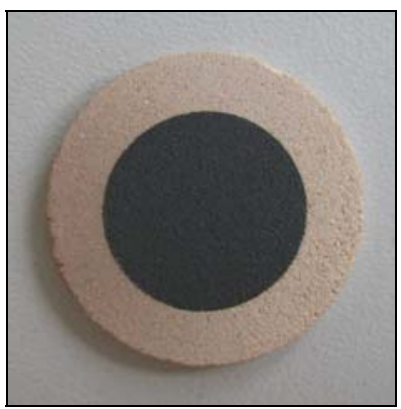

(c)

Figure 6. Micrograph of LSCF48 feedstock powder (a) and plasma sprayed oxygen electrode (b). Photograph of plasma sprayed cathodic symmetrical cell (c).

The improvement was also observed in the impedance spectra as seen in Figure 7, in which the ohmic resistance of the electrolyte was reduced by a quarter, and polarization resistance by half the value. Figures $6 \mathrm{c}$ and 7 show respectively a top view and a crosssection image of a cathodic half cell with plasma sprayed LSCF48 cathodes on both sides of a pre-sintered YDC15 electrolyte. The substrates having inhomogeneous porosity within its thickness appeared to be sensitive to the heat shocks imposed to it by the plasma. By adjusting the spraying parameters for these ceramic electrolytes, cathodic symmetrical cells were satisfactorily achieved.
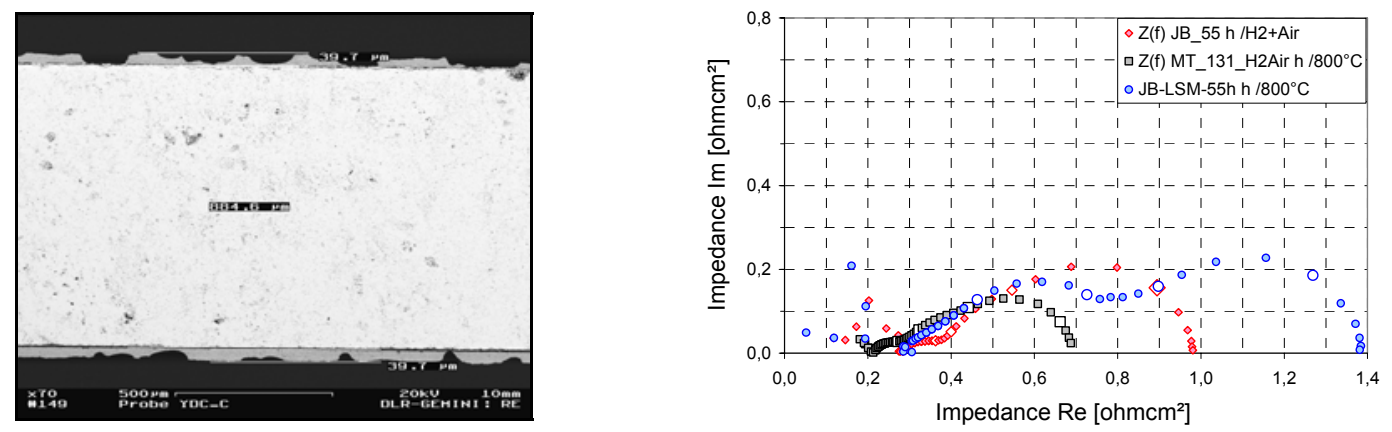

Figure 7. Oxygen electrodes deposited onto SOFC half cells produced by plasma spraying. Cross section SEM image and impedance.

After reaching acceptable power densities with these powders it is also planned to use LSC40 as an alternative material. In addition, a comparative impedance study of electrolyte supported cathodic half cells with electrodes deposited either by TC and PS was performed. The electrolyte pellets were prepared following one and the same technological regime of cold pressing and sintering. The impedance measurements were carried out in a wide temperature range $\left(100-800^{\circ} \mathrm{C}\right)$, which ensures information about the bulk and grain boundary behaviour of the electrolyte. Figure 9 presents experimental data for the two deposition approaches. It is interesting to notice that the plasma spraying procedure influences the electrolyte microstructure, increasing the grain boundary contribution. The stronger deformation of the corresponding semicircle correlates with enhancement of the microstructural inhomogeneity (Figure 8a). Although the electrolyte resistivity after plasma spraying slightly increases, the activation energy remains the same for both samples, decreasing from $0.9 \mathrm{eV}$ at temperatures below $450^{\circ} \mathrm{C}$ down to 0.6 
$\mathrm{eV}$ at temperatures above $450^{\circ} \mathrm{C}$ (Figure 9). The area specific resistance of the cathode has different temperature behaviour depending on the applied technique of deposition. At about $500^{\circ} \mathrm{C}$ it is higher for the electrodes obtained by Tape Casting (Figure $8 \mathrm{~b}$ ), while at higher temperatures it becomes lower (Figure 8c,d).

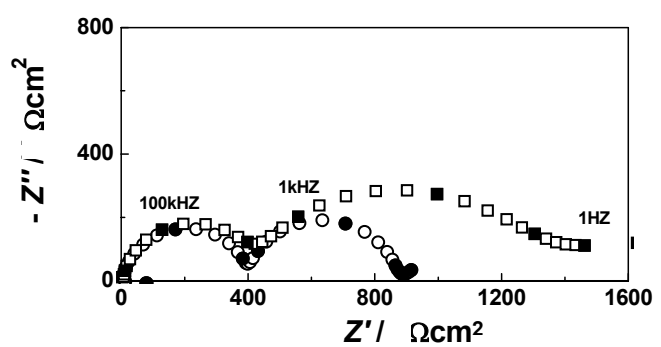

(a)

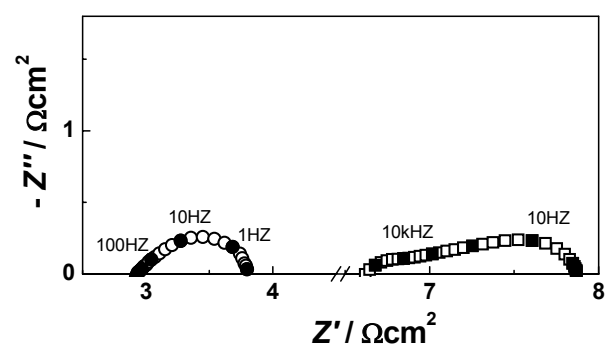

(c)

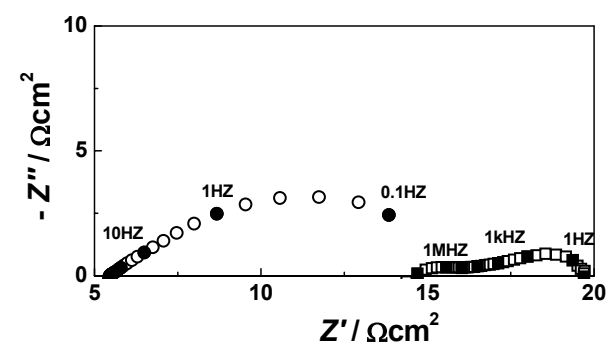

(b)

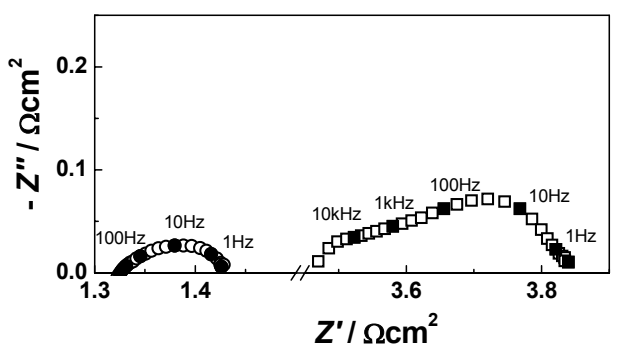

(d)

Figure 8. Complex plane impedance diagrams of cathodic half cells with electrodes deposited by TC $(\diamond)$ and PS ( $\square$ ) at different temperatures: (a) $202^{\circ} \mathrm{C}$; (b) $626^{\circ} \mathrm{C}$; (c) $727^{\circ} \mathrm{C}$; (d) $820^{\circ} \mathrm{C}$.

The impedance studies inform also for differences in the mechanism of the cathode reaction. For the tape casting technique a single arc is observed with a shape suggesting transport limitations (bounded), while for the plasma sprayed sample additional higher frequency step is observed. For a deeper and more precise analysis of the reaction mechanism and electrolyte behaviour, correction of the errors coming from the parasitic inductance and resistance of the cell will be performed. Some of the data will be analyzed by the technique of the Differential Impedance Analysis (10), which does not need a preliminary working hypothesis for the phenomena under study.

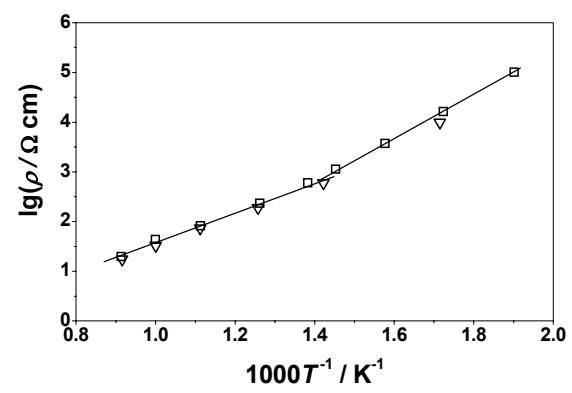

Figure 9. Arrhenius plots for cathodic half cells with electrodes deposited by Plasma Spraying ( $\square$ ) and Tape Casting $(\nabla)$. 


\section{Conclusions}

Prototypes for the IDEAL-Cell project were fabricated. Thick multilayer structures were successfully obtained both by cold pressing and spark plasma sintering, while complete cells were fabricated by non aqueous tape casting and co-firing. Sintering temperature of $\mathrm{BCY}$ and YDC was significantly reduced by the addition of $\mathrm{ZnO}$ or $\mathrm{B}_{2} \mathrm{O}$ and $\mathrm{Li}_{2} \mathrm{CO}_{3}$. Cathodic ceria-based half cells were also prepared by cold pressing and LSCF electrodes were deposited by plasma spray or tape casting. Impedance measurements on half cells indicated high efficiency of LSCF electrodes with a better performance in the case of tape casting.

\section{Acknowledgments}

Powders were fabricated and supplied by Marion Technologies. The research leading to these results has received funding from the European Community's Seventh Framework Programme (FP7/2007-2013) under grant agreement No 213389.

\section{References}

1. P. Holtappels, U. Vogt and T. Graule, Adv. Eng. Mater., 7, 292 (2005).

2. A.S. Thorel, A. Chesnaud, M. Viviani, A. Barbucci, S. Presto, P. Piccardo, Z. Ilhan, D. Vladikova, Z. Stoynov, IDEAL-Cell, a high temperature Innovative Dual mEmbrAne fuel-Cell, this issue.

3. T. Ou, F. Delloro, C. Nicolella, W. G. Bessler, and A.S. Thorel, Mathematical model of mass and charge transport and reaction in the central membrane of the IDEAL-Cell, this issue.

4. G. Caboche, J.-F. Hochepied, P. Piccardo, K. Przybylski, R. Ruckdäschel, M.-R. Ardigó, E. Fatome, S. Chevalier, A. Perron, L. Combemale, M. Palard, J. Prazuch, T. Brylewski, Compatibility and reactivity between materials in an Innovative Dual mEmbrAne fueL-Cell (IDEAL-Cell) design, this issue

5. R. Costa, J. Hafsaoui, A.P. Almeida de Oliveira, A. Grosjean, M. Caruel, A. Chesnaud, A. Thorel, J. Appl. Electrochemistry, 39, 48 (2009)

6. O.A. Shlyakhtin, A.V. Orlov, Y.-J. Oh, J. Electroceramics, 17, 405 (2006).

7. Z. Shen, Z. Zhao, H. Peng, and M. Nygren, Nature, 417, 266 (2002).

8. C. Elissalde, M. Maglione, C. Estournes, J. Am. Ceram. Soc., 90, 973 (2007).

9. A. Ansar, Z. Ilhan, G. Schiller, O. Patz, J. B. Gregoire, in International Thermal Spray Conference (ITSC) 2008 Proceedings, E. Lugschneider, Editors, Maastricht, The Netherlands (2008).

10. Z. Stoynov, D. Vladikova, Differential Impedance Analysis, Marin Drinov Academic Publishig House, 2005, Sofia.

11. K.D. Kreuer, Annu. Rev. Mater. Res., 33, 333 (2003). 